\title{
Morfologia de Hidrogéis-IPN Termo-sensíveis e pH-responsivos para Aplicação como Biomaterial na Cultura de Células
}

\author{
Adley F. Rubira, Edvani C. Muniz \\ Departamento de Química, UEM \\ Marcos R. Guilherme, Alexandre T. Paulino, Elias B. Tambourgi \\ Faculdade de Engenharia Química, UNICAMP
}

\begin{abstract}
Resumo: No presente trabalho, foram sintetizados hidrogéis com ambas as propriedades, termo-sensíveis e pH-responsivos, pela formação de redes de alginato de cálcio (alginato-Ca) dentro de redes de poli(N-Isopropil Acrilamida) (PNIPAAm), resultando em um sistema IPN (sistema de redes poliméricas interpenetradas). Através das análises por microscopia de varredura eletrônica (MEV) e ensaios de intumescimento foi possível observar que os hidrogéis IPN exibiram forte contração quando aquecidos acima da LCST (temperatura critica inferior de solubilização) da PNIPAAm, ou seja, acima de temperaturas de $30-35^{\circ} \mathrm{C}$. Observou-se ainda que devido à contração do hidrogel, houve uma diminuição significativa nos tamanhos de poros os quais foram observados pelas micrografias. Observou-se também que no intervalo de $\mathrm{pH}$ estudado os hidrogéis de IPN sofreram significativa variação da estrutura com a variação desse parâmetro. Tal efeito foi atribuído à presença de grupos químicos carregados com alginato, os quais possuem carga elétrica negativa. Os resultados indicaram que o hidrogel formado por alginato-Ca e PNIPAAm possuíram características especificas após variação de pH e temperatura, e que tais características são derivadas dos compostos individuais envolvidos na síntese. Nesse caso, as propriedades de alginato-Ca e PNIPAAm livres foram preservadas dentro do hidrogel. Tal hidrogel ficou mais resistente à aplicação de uma tensão de compressão. Como conclusão, observou-se que os hidrogéis apresentaram morfologia característica para variações controladas de $\mathrm{pH}$ e temperatura, podendo ser eficientemente aplicados como biomaterial na cultura de células.
\end{abstract}

Palavras-chave: Hidrogel, termo-sensível, pH-responsivo, morfologia, cultura de células.

\section{Morphology of Temperature-sensitive and pH-responsive IPN-hydrogels for Application as Biomaterial for Cell Growth}

\begin{abstract}
In the present investigation, hydrogels with $\mathrm{pH}$-responsive and temperature-sensitive properties were obtained by formation of alginate-Ca network inside the PNIPAAm network resulting in an interpenetrated network system (IPN). From scanning electron microscopy (SEM) images and water uptake (WU) tests one observed that IPN hydrogels exhibited a drastic shrinking when heated above $30-35^{\circ} \mathrm{C}$. The shrinking resulted in decreased average pore size, thus affect the hydrogel morphology significantly. In the $\mathrm{pH}$ range studied, IPN hydrogels showed significant $\mathrm{pH}$ dependence, which was attributed to the charged alginate groups. The results indicated that the $\mathrm{pH}$-responsiveness and temperature-dependence of alginate and PNIPAAm, respectively, were preserved in IPN hydrogels. In addition, such hydrogels become less deformable when subjected to compressive stress. These hydrogels presented porous morphology that may be tuned by controlling the temperature, and this makes them attractive for applications as biomaterial in cell growth.
\end{abstract}

Keywords: Hydrogels, temperature-sensitivity, pH-responsive, morphology, cell growing.

\section{Introdução}

Hidrogéis de alginato são obtidos a partir do ácido algínico, o qual é encontrado nas paredes das células de algas marrons $^{[1,2]}$. O ácido algínico é um polímero linear de alta massa molar com seções rígidas e regiões flexíveis. É formado por monômeros de ácido $\beta$-D-manurônico (M) e ácido
$\alpha$-L-glucurônico (G) ambos ligados de forma linear por interações glicosídicas $\alpha(1-4)$ contendo três tipos de estruturas de blocos: blocos de ácido $\beta$-D-manurônico (M), blocos de ácido $\alpha$-L-glucurônico $(\mathrm{G})$, e uma mistura dos dois blocos $(\mathrm{MG})^{[3]}$. Tal composto apresenta afinidade para vários cátions metálicos tais como $\mathrm{Ca}^{2+}, \mathrm{K}^{+}$e $\mathrm{Na}^{+[2]}$. Quando associado a íons $\mathrm{Na}^{+}$recebe o nome de alginato de sódio (alginato-Na),

Autor para correspondência: Alexandre T. Paulino, Faculdade de Engenharia Química, Departamento de Engenharia de Sistemas Químicos, UNICAMP, R. Albert Einstein 500, CEP: 13081-970, Campinas, SP, Brasil. E-mail: atpaulino10@gmail.com 
cujo composto apresenta grande solubilidade em soluções aquosas. A interação entre os grupos carboxilatos do ácido algínico e cátions divalentes como, por exemplo, o cálcio $\left(\mathrm{Ca}^{2+}\right)$, induz a formação de géis em soluções aquosas ${ }^{[4]}$. Neste caso, a rede polimérica passa a ser identificada como alginato de cálcio (alginato-Ca). O hidrogel de alginato-Ca é utilizado para aplicações endovasculares, no transplante de células, imobilização de enzimas, entre outras ${ }^{[5,6]}$. O grande interesse de muitos pesquisadores da área biomédica nos hidrogéis de alginato-Ca deve-se a sua comprovada biocompatibilidade, hidrofilicidade e baixo custo ${ }^{[7,8]}$. Outro polímero potencialmente viável para aplicações na área de biomateriais, é o PNIPAAm ${ }^{[9-12]}$. Esse polímero tem sido muito estudado porque apresenta insolubilidade em água quando aquecido. Tal insolubilidade é resultado de um diagrama de fases do tipo LCST $^{[13,14]}$. Em água, a transição de fase da PNIPAAm ocorre em temperaturas entre $30-35^{\circ} \mathrm{C}^{[14]}$. Entretanto, hidrogéis baseados nesse polímero são mecanicamente ruins quando intumescidos ${ }^{[15]}$. Uma alternativa para minimizar este problema é a associação do PNIPAAm e de alginato-Ca no mesmo hidrogel. Para isso, foi adotado nesse trabalho o método de síntese baseado em rede polimérica interpenetrada (IPN). Tal método consiste em interpenetrar duas redes poliméricas formando uma estrutura final mecanicamente estável ${ }^{[16]}$. O objetivo desse trabalho foi sintetizar uma matriz polimérica mecanicamente estável e inteligente ${ }^{[17-22]}$, ou seja, que apresente excelente resistência mecânica além das propriedades termo-sensível (do PNIPAAm) e pH-responsivo (do alginato-Ca). Neste sentido, os hidrogéis-IPN sintetizados foram intumescidos em diferentes soluções aquosas de $\mathrm{pH}$ 4,0, 7,0 e 10,0 com o intuito de verificar se as propriedades do alginato foram preservadas no hidrogel. As características do PNIPAAm no hidrogel foram investigadas baseando-se em mudanças morfológicas na superfície do hidrogel, induzida pelo colapso das cadeias de PNIPAAm em temperaturas próximas a LCST. Para isso, micrografias da superfície do hidrogel foram obtidas em diferentes temperaturas por meio de microscopia eletrônica de varredura (MEV). A análise da tensão de compressão foi realizada utilizando um texturômetro.

\section{Materiais e Métodos}

\section{Materiais}

NIPAAm(Adrich),N,N'-metileno-bis-acrilamida,MBAAm (Plusone), N,N,N'N'-tetrametiletilenodiamina TEMED, (Adrich), persulfato de sódio (Aldrich), alginato-Na (Aldrich) com razão entre ácido manurônico e ácido glucurônico (M/G) de 1,56. Mi- croscópio eletrônico de varredura (modelo SS-550 Superscan), liofilizador (Christ gefriertrocknungsanlagen), Texturômetro (Stevens-L.F.R.A).

\section{Preparação dos hidrogéis}

Foram preparadas soluções aquosas contendo o monômero NIPAAm, o agente reticulante N,N'-metileno-bis-acrilamida (MBAAm), o catalisador N,N,N'N'-tetrametiletilenodiamina (TEMED) e o alginato-Na. O teor de cada componente usado na síntese dos hidrogéis está descrito na Tabela 1. Tais soluções aquosas foram desoxigenadas por 15 minutos sendo em seguida adicionadas quantidades conhecidas de uma solução de persulfato de sódio. Subseqüentemente, a mistura foi inserida entre duas placas de vidro em formato quadrado, contendo 0,12 m de aresta, separadas por um espaçador de borracha de 1,5 $\mathrm{mm}$. Esse sistema foi mantido à temperatura ambiente por um período de 24 horas. Após esse período, foi removida uma das placas de vidro e em seguida o sistema foi imerso em soluções de cloreto de cálcio por mais 72 horas. Após, o hidrogel foi transferido para um béquer contendo $500 \mathrm{~mL}$ de água deionizada para remover os íons cálcio $\left(\mathrm{Ca}^{2+}\right)$ em excesso, permanecendo assim por 24 horas em temperatura ambiente. A concentração de $\mathrm{Ca}^{2+}$ foi mantida entre 1 e 5\%. Para identificar os hidrogéis, foi adotada a notação (A-C-P), onde A, C e P representam concentrações, em $\% \mathrm{~m} / \mathrm{v}$, de alginato-Na, cloreto de cálcio e de PNIPAAm, respectivamente, nas soluções usadas para a síntese.

\section{Medidas de intumescimento}

Os ensaios de intumescimento foram investigados em soluções tampão de pH 4,0, 7,0 e 10,0. A força iônica foi controlada e mantida constante usando uma solução de $\mathrm{NaCl}$ 0,1 mol.L $\mathrm{L}^{-1}$. Para avaliar o efeito da temperatura, realizou-se o intumescimento entre 25 e $40{ }^{\circ} \mathrm{C}$. Em cada medida o hidrogel permaneceu em contato com a solução por 48 horas e a massa foi medida após esse período. O grau de intumescimento (I) foi determinado através da Equação 1:

$$
I=\frac{M_{i}}{M_{s}}
$$

onde $\mathrm{M}_{\mathrm{i}}$ é massa do hidrogel intumescido e $\mathrm{M}_{\mathrm{s}}$, é a massa do hidrogel seco.

\section{Determinação da morfologia dos hidrogéis}

Os hidrogéis foram intumescidos em água nas temperaturas de $25,30,35$ e $40^{\circ} \mathrm{C}$. Após esse período, as amostras intu-

Tabela 1. Quantidades de Alginato, $\mathrm{CaCl}_{2}$, NIPAAm e MBAAm usadas na síntese dos hidrogéis

\begin{tabular}{ccccc}
\hline Hidrogels & Alginato $\left(\mathbf{x ~ 1 0} \mathbf{~ m o l . m L}^{-1}\right)$ & $\mathbf{C a C l}_{2}{ }^{*}\left(\mathbf{m M o l}_{\mathbf{m}} \mathbf{m L}^{-1}\right)$ & NIPAAm $_{\left(\mathbf{m M o l} . \mathbf{m L}^{-1}\right)}$ & MBAAm $\left._{(\mathbf{m M o l} . \mathbf{m L}}{ }^{-1}\right)$ \\
\hline$(1-1-0)$ & 7,7 & 68,0 & 0 & 0 \\
$(1-1-2.5)$ & 7,7 & 68,0 & 220,9 & 2,2 \\
$(1-1-5)$ & 7,7 & 68,0 & 441,9 & 4,4 \\
$(1-1-10)$ & 7,7 & 68,0 & 883,7 & 8,8 \\
\hline
\end{tabular}

*Quantidade inicial de $\mathrm{CaCl}_{2}$ usado na formação do alginato-Ca. 
mescidas foram congeladas em nitrogênio liquido à $-180{ }^{\circ} \mathrm{C}$ e liofilizadas durante 24 horas por um liofilizador operando em $-60{ }^{\circ} \mathrm{C}$. Após a secagem, realizou-se o depósito de uma fina película de ouro sobre a superfície das amostras secas as quais foram conduzidas até um microscópio de varredura eletrônica para obter os resultados das suas morfologias.

\section{Medidas da resistência mecânica dos hidrogéis}

A resistência mecânica do hidrogel formado, baseada em medidas de compressão, foi realizada em texturômetro (Stevens-L.F.R.A) mantendo-se a profundidade de indentação de $1 \mathrm{~mm}$ e velocidade descendente do corpo de prova de $0,2 \mathrm{~mm} \cdot \mathrm{s}^{-1}$. A tensão máxima de compressão, $\sigma_{\text {máx }}$, foi obtida por meio da Equação 2 e foi considerada como a força máxima requerida para que haja a deformação elástica do gel, a qual foi fixada em $1 \mathrm{~mm}$.

$$
\sigma=\frac{f}{S_{0}}=E\left(\lambda-\lambda^{2}\right)
$$

onde $\sigma$ é a tensão aplicada, em Pa.m ${ }^{-2}$, f é o valor da força exercida, $\mathrm{S}_{0}$ é a área do corpo de prova que comprime o hidrogel e $\lambda$ é a deformação relativa.

\section{Resultados e Discussão}

\section{Estrutura do hidrogel IPN de alginato-Ca e PNIPAAm}

Através do procedimento de síntese dos hidrogéis semi-IPN previamente descrito por Moura et al. ${ }^{[23]}$ foi possível obter a reticulação do alginato-Na utilizando uma solução de cloreto de cálcio a fim de formar o alginato-Ca reticulado. Na sequiência, PNIPAAm sem retículos foi entrelaçada dentro da rede do alginato-Ca. A diferença de tais hidrogéis com aqueles da classe IPN, sintetizados no presente trabalho, são basicamente referentes às suas estruturas poliméricas tridimensionais obtidas. Os hidrogéis-IPN teve as suas redes de alginato e PNIPAAm reticuladas, com cloreto de cálcio e MBAAm, respectivamente, formando uma única rede polimérica tridimensional final com a PNIPAAm interpenetrada dentro da rede de alginato. Assim, a estrutura do material final obtido bem como a sua propriedade morfológica e mecânica foi diferente daquela obtida para hidrogel semi-IPN observado previamente ${ }^{[23]}$. O hidrogel final formado na presente síntese consiste de uma mistura de três redes poliméricas, ou seja, a rede de PNIPAAm reticulada com MBAAm e interpenetrada na rede de alginato reticulado. Nesse caso foi possível a obtenção de um único hidrogel com retículos físicos, no caso da reticulação do alginato-Na com cloreto de cálcio, e com retículos químicos, no caso da reticulação da PNIPAAm com MBAAm.

\section{Efeito da temperatura no intumescimento dos hidrogéis}

Os hidrogéis-IPN sofreram significativa variação no grau de intumescimento quando aquecidos em temperaturas superiores a LCST do PNIPAAm conforme observado

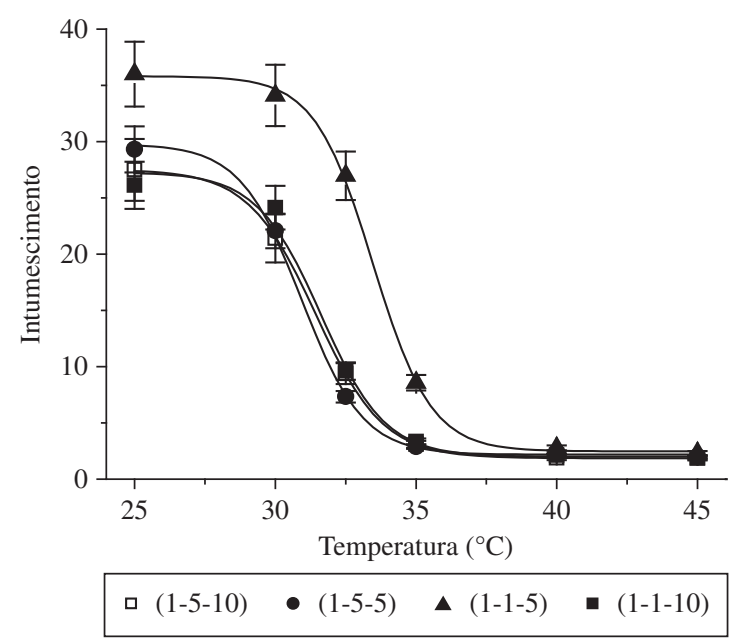

Figura 1. Intumescimento de hidrogéis-IPN (1-C-P) em função da temperatura.

na Figura 1. Nas temperaturas superiores a LCST, a rede do PNIPAAm dentro do hidrogel pode colapsar e conseqüentemente, arrastar de volta a rede de alginato- $\mathrm{Ca}^{[24]}$. Apesar de mecanicamente resistente, a rede de alginato-Ca é flexível ${ }^{[25]}$. $\mathrm{O}$ efeito de contração torna-se mais significativo quando a concentração de PNIPAAm no hidrogel é 5\%. Contudo, para concentrações de PNIPAAm na faixa dos $10 \%$, o efeito de contração do hidrogel diminui, pois neste caso, a alta densidade de cadeias dificulta a contração da matriz polimérica ${ }^{[19]}$. Outro fator importante a ser considerado é o grau de reticulação do hidrogel, o qual contribuiu para uma redução no processo de contração do material. Isto pode ser observado na curvas (1-5-10) e (1-1-10), representadas na Figura 1.

\section{Efeito da temperatura na morfologia dos hidrogéis}

O brusco decréscimo observado no intumescimento dos hidrogéis induz modificações significativas na morfologia destes materiais, como será apresentado a seguir. Neste trabalho, observou-se que os hidrogéis-IPN constituídos de alginato-Ca/PNIPAAm são altamente porosos e tal característica foi fortemente dependente das variações de temperatura $^{[18]}$. Na Figura 2 estão apresentadas às micrografias obtidas para o hidrogel (1-1-5) liofilizado depois de intumescido até o equilíbrio, nas condições já previamente indicadas. Em temperatura inferior a LCST, neste caso a $25^{\circ} \mathrm{C}$, o hidrogel apresentou uma estrutura altamente porosa. Essa característica está diretamente relacionada ao intumescimento do hidrogel. Quando imerso em um meio aquoso, tais hidrogéis, os quais possuem grupos hidrofílicos e são porosos, permitem a difusão rápida de um determinado solvente para o interior da matriz. Assim, ocorre um contato quase que imediato entre o solvente e as cadeias poliméricas. Por outro lado, ao ser intumescido nas temperaturas acima de $30{ }^{\circ} \mathrm{C}$, o hidrogel passa a apresentar alterações em sua constituição morfológica. Isto foi detectado através das medidas dos valores do tamanho médio de poros $(\phi)$ na superfície do hidrogel. Tal parâmetro foi determinado estatisticamente 

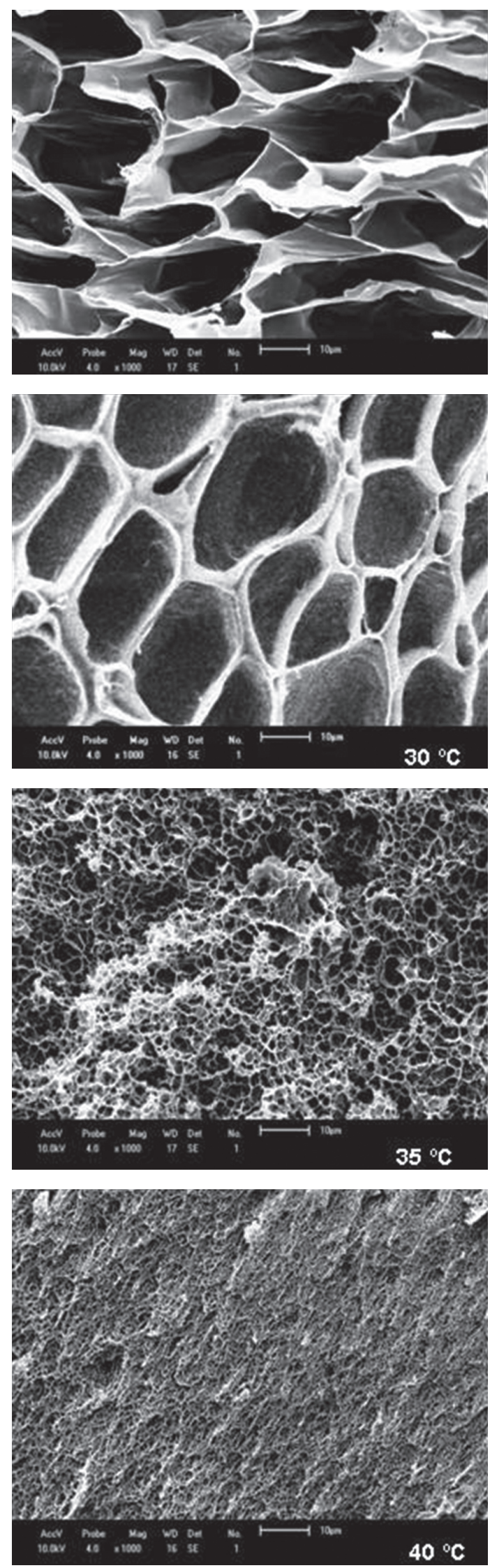

Figura 2. Micrografias obtidas para o hidrogel-IPN (1-1-5), liofilizado após intumescer até o equilíbrio, nas temperaturas indicadas, em $\mathrm{N}_{2}$ líquido. utilizando como referência a barra indicativa de ampliação, descrita em cada micrografia. A $25{ }^{\circ} \mathrm{C}$ o valor de $\phi$ foi de aproximadamente $32 \pm 5 \mu \mathrm{m}$, enquanto que a $30^{\circ} \mathrm{C}$, o valor de $\phi$ foi de aproximadamente $25 \pm 4 \mu \mathrm{m}$, um indicativo da contração do hidrogel. Porém, foi a $35^{\circ} \mathrm{C}$ que o hidrogel passou a apresentar uma morfologia completamente distinta das anteriores, nesse caso, tendo um valor de $\phi$ de aproximadamente $1,8 \pm 0,5 \mu \mathrm{m}$. Por fim, a $40{ }^{\circ} \mathrm{C}$ foi visualizada uma superfície praticamente compacta com pequeníssimos poros, nesse caso, valores próximos de 0,6 $\pm 0,1 \mu \mathrm{m}$. Observou-se então pelos resultados que o processo de contração do hidrogel é gradual e se intensifica acima de $35^{\circ} \mathrm{C}$. Conclusivamente, sugeriu-se que durante a transição de fase, as cadeias de PNIPAAm colapsam e arrastam simultaneamente as redes do alginato-Ca. Durante esse processo, as cadeias que compõem a rede polimérica (alginato e PNIPAAm) são reordenadas ocupando os espaços vazios que estavam preenchidos com moléculas de água a $25 \mathrm{e} / \mathrm{ou}$ a $30^{\circ} \mathrm{C}$.

Os tamanhos de poros afetam grandemente a difusão de íons para dentro da matriz polimérica. Sendo assim, quanto maior os tamanhos de poros, mais íons irão se difundir para o interior do hidrogel. Considerando as amostras analisadas com o procedimento demonstrado na metodologia 2,4 , podese considerar que os poros do hidrogel permaneceram abertos mesmo depois da secagem. Ainda, o intumescimento e o consequiente congelamento do hidrogel utilizando nitrogênio líquido a $-180{ }^{\circ} \mathrm{C}$, e a secagem por liofilização, podem garantir que os tamanhos de poros analisados na amostra seca sejam praticamente os mesmos daqueles quando a amostra está intumescida. Nessa lógica, considerou-se nesse trabalho que os tamanhos de poros analisados para a amostra no estado sólido foram similares aqueles os quais foram observados quando a amostra estava intumescida ao equilíbrio.

$\mathrm{Na}$ micrografia obtida para o hidrogel de alginato-Ca puro (1-1-0), ilustrada na Figura 3a, observou-se uma superfície "folheada", morfologia típica de alginato- $\mathrm{Ca}^{[26,27]}$, e com pequenos poros, independentemente da temperatura. $\mathrm{O}$ hidrogel de PNIPAAm puro (0-0-5), Figura 3b, apresentou uma superfície com poros distribuídos heterogeneamente. Os tamanhos médios dos poros destes materiais não foram determinados em virtude da presença de poros com forma muito irregular.

\section{Efeito da pH no intumescimento dos hidrogéis}

Na Figura 4 estão ilustradas as curvas que representam o efeito do $\mathrm{pH}$ no grau de intumescimento dos hidrogéis (1-C-P). Observa-se que as quantidades de PNIPAAm e de íons $\mathrm{Ca}^{2+}$ presentes no hidrogel influenciaram significativamente os índices de intumescimento. A sensibilidade do hidrogel ao $\mathrm{pH}$ diminuiu quando o teor de PNIPAAm aumentou. Isto foi atribuído à formação de hidrogel com estrutura polimérica mais compacta. Outro fato que fica evidente é o comportamento em forma de "V" apresentado pelas curvas de intumescimento. Nesse caso, os hidrogéis intumesceram mais em meios ácido e alcalino do que em meio neutro. Em meio ácido, os íons $\mathrm{Ca}^{2+}$ presentes nos grupos -COO-Ca-OOC- do alginato-Ca foram substituí- 


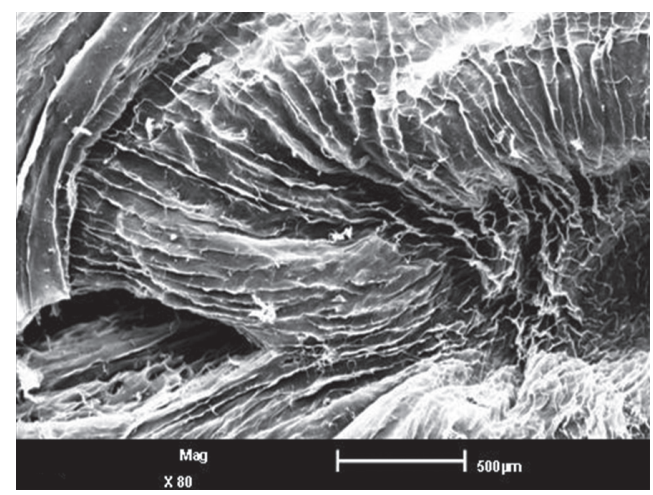

(a)

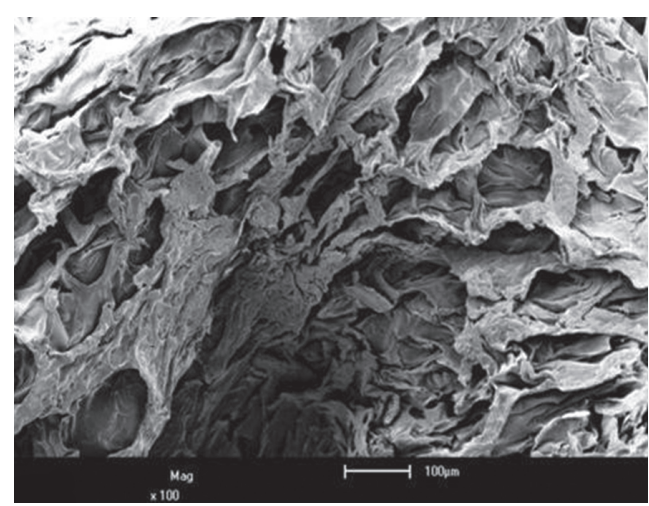

(b)

Figura 3. Micrografias obtidas para o hidrogéis de a) alginato puro (1-1-0); e b) PNIPAAm puro (0-0-5), liofilizados após intumescerem até o equilíbrio a $25^{\circ} \mathrm{C}$, em $\mathrm{N}_{2}$ líquido.

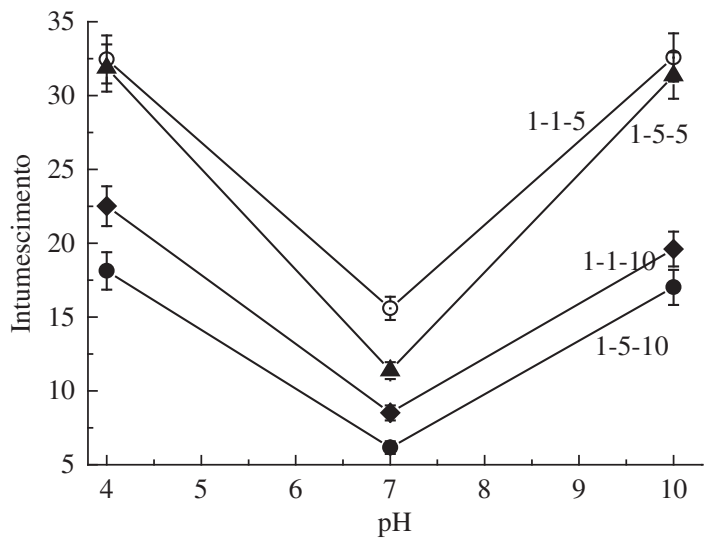

Figura 4. Intumescimento de hidrogéis-IPN (1-C-P) em função do pH.

dos por $\mathrm{H}^{+}$formando grupos - $\mathrm{COOH}$. Nestas condições, a rede polimérica do alginato-Ca se desfaz parcialmente aumentando a mobilidade dos segmentos poliméricos que interagem mais facilmente com o solvente. Em meio neutro, as concentrações de $\mathrm{H}^{+}$e $\mathrm{OH}^{-}$são equivalentes. Sendo assim, os íons $\mathrm{OH}^{-}$interagem com os íons $\mathrm{H}^{+}$presentes nos grupos - $\mathrm{COOH}$ do hidrogel, induzindo a formação de grupos -COO-Ca-OOC-. Isto reflete diretamente em um aumento no grau de reticulação do hidrogel, o que reduz significativamente os valores de intumescimento. Acima de $\mathrm{pH} 7$, os íons $\mathrm{OH}^{-}$atuarão sobre os íons $\mathrm{Ca}^{2+}$ presentes nos grupos -COO-Ca-OOC- do hidrogel formando grupos - $\mathrm{COO}$. Estes grupos geram repulsão eletrostática entre os segmentos poliméricos do alginato aumentando o contato entre o hidrogel e solvente. Cabe ressaltar que o efeito do pH nos hidrogéis-IPN de alginato-Ca/PNIPAAm é reversível, isto é, o mesmo valor de intumescimento é obtido quando o hidrogel retorna ao $\mathrm{pH}$ original. Hidrogéis com respostas as variações de $\mathrm{pH}$ e temperatura tem sido extensivamente estudados dentro da classe dos chamados "materiais inteligentes" os quais tem sido aplicados em tratamento de águas e efluentes industriais, liberação controlada de drogas, membranas de separação, dentre muitos outros ${ }^{[17-20,24]}$.

\section{Analise da propriedade mecânica do hidrogel}

Através da Figura 5, pode ser observada a dependência da tensão de compressão com a temperatura em diferentes composições do hidrogel. Nota-se que a tensão de compressão aumentou proporcionalmente com o aumento de temperatura, independente da quantidade de PNIPAAm no hidrogel. Contudo, um aumento mais significativo tem sido visualizado quando o hidrogel foi aquecido acima da LCST da PNIPAAm (acima de $30{ }^{\circ} \mathrm{C}$ ). Comparando esses resultados com aqueles obtidos para os ensaios de intumescimento, pode-se concluir que os hidrogéis constituídos de alginato são mais densos. Porém, os hidrogéis constituídos de PNIPAAm possuem maior resistência mecânica. Observa-se ainda que a tensão de compressão para os hidrogéis (1-1-5) e (1-1-10) possui praticamente a mesma ordem de magnitude em temperaturas mais elevadas (acima de $45^{\circ} \mathrm{C}$ ). Contudo, ambos os valores de tensão de compressão para os hidrogéis (1-1-5) e (1-1-10) são significantemente superiores daqueles observados para o hidrogel (1-1-0), cujo é constituído apenas por alginato. Por fim, as propriedades mecânicas dos hidrogéis são dependentes das quantidades de alginato-Ca e das redes de PNIPAAm para temperaturas abaixo da LCST. Por outro lado, para temperaturas acima da LCST, a resistência mecânica é dependente somente das quantidades de PNIPAAm utilizadas durante a síntese.

\section{Motivação}

Os resultados apresentados neste trabalho indicaram que as características do alginato e PNIPAAm foram preservadas

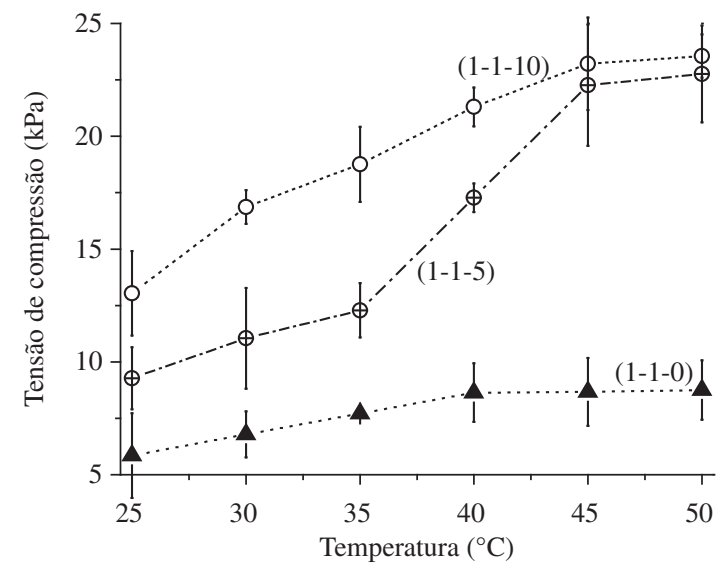

Figura 5. Resultados da tensão de compressão versus temperatura para os hidrogéis (1-1-0), (1-1-5) e (1-1-10). 
no hidrogel-IPN. Além disso, é importante enfatizar que o hidrogel contraído a $40^{\circ} \mathrm{C}$ pode ser expandido novamente ao ser resfriado para $25^{\circ} \mathrm{C}$. Por ser esse comportamento controlável e reversível, hidrogéis-IPN de alginato-Ca/PNIPAAm são potencialmente viáveis para aplicações como substrato em sistemas de crescimento de células. Por exemplo, células aderentes cultivadas na superfície porosa do hidrogel seriam descoladas por meio de alterações morfológicas induzidas por estímulos térmicos. Este novo procedimento evita o inconveniente dos métodos convencionais que emprega reagentes químicos para descolar células de substratos. Alem disso, hidrogéis-IPN podem atuar como membranas para aplicações em processo de separação e como biomateriais na medicina, farmácia e biologia.

\section{Conclusões}

Hidrogéis-IPN, constituídos de redes de PNIPAAm em redes de alginato-Ca, sofrem significativa variação no grau de intumescimento e na tensão de compressão quando aquecidos acima da LCST do PNIPAAm. O brusco decréscimo observado no intumescimento dos hidrogéis induz modificações significativas na morfologia destes materiais. Em temperaturas inferiores a LCST, o hidrogel apresenta uma estrutura altamente porosa. Acima da LCST, o hidrogel passou a apresentar uma morfologia distinta com tamanho médio de poros menores. Os hidrogéis intumescem em maior grau quando estão em meios ácidos e alcalinos do que quando estão em meio neutro, demonstrando sensibilidade à variação de $\mathrm{pH}$. A resistência mecânica dos hidrogéis é regida pela quantidade de PNIPAAm quando utilizado um intervalo de temperatura entre 25 e $50{ }^{\circ} \mathrm{C}$. O efeito da variação da tensão de compressão é observado com maior intensidade em temperaturas acima da LCST da PNIPAAm. Os resultados apresentados neste trabalho indicaram que as características do alginato e PNIPAAm foram preservadas no hidrogel-IPN. Por essa razão, esses hidrogéis são potencialmente viáveis para aplicações na área de biomateriais, por exemplo, como substrato para cultura de células.

\section{Agradecimentos}

MRG, ATP e EBT agradecem a FAPESP pela concessão de bolsas de pós-doutorado. ECM e AFR são gratos a CAPES, CNPq e a Fundação Araucária pelo auxílio financeiro.

\section{Referências Bibliográficas}

1. Wang, X. \& Spencer, G. - Polymer, 39, p.2759 (1998).

2. Meeuse, B. J. D. - "Composition of Cell and Metabolic Products", University of Washington, Washington (1962).

3. Draget, K. I.; Skjåk-Braek, G. \& Smidsrød, O. - Inter. J. Biol. Macromol., 21, p.47 (1997).

4. Halder, A.; Maiti, S. \& Sa, B. - Inter. J. Pharm., 302, p.84 (2005).
5. Shapiro, L. \& Cohen, S. - Biomaterials, 18, p.583 (1997).

6. Li, S.; Wang, X. T.; Zhang, X. B.; Yang, R. J.; Zhang, H. Z.; Zhu, L. Z. \& Hou, X. P. - J. Control. Release, 84, p.87 (2002).

7. Hurteaux, R.; Edwards-Lévy, F.; Laurent-Maquin, D. \& Lévy, M. C. - Eur. J. Pharm. Sci., 24, p.187 (2005).

8. Chretien, C. \& Chaumeil, J. C. - Inter. J. Pharm. 304, p.18 (2005).

9. Liu, L. \& Sheardown, H. - Biomaterials, 26, p.233 (2005).

10. Cho, J. H.; Kim, S. H.; Park, K. D.; Jung, M. C.; Yang, W. I.; Han, S. W.; Noh J. Y. \& Lee, J. W. J. W. - Biomaterials, 25, p.5743 (2004).

11. Kavanagh, C. A.; Rochev, Y. A.; Gallagher, W. M.; Dawson, K. A. \& Keenan, A. K. - Pharmacol \& Therapeutics, 102, p.1 (2004).

12. Guilherme, M. R.; Reis, A. V.; Rubira, A. F. \& Muniz, E. C. - www.inpi.gov.br, PI 0503651-8, Brazil (2005).

13. Guilherme, M. R.; Campese, G. M.; Radovanovic, E.; Rubira, A. F.; Tambourgi, E. B. \& Muniz, E. C. - J. Membrane Sci. 275, p.187 (2006).

14. Schild, H. G. - Prog. Polym. Sci., 17, p.163 (1992).

15. Takigawa, T.; Yamawaki, T.; Takahashia, K. \& Masuda, T. - Polym. Gels Networks, 5, p.585 (1997).

16. Athawale, V. D. \& Raut, S. S. - Eur. Polym. J. 38, p.2033 (2002).

17. Jin, S. P.; Liu, M. Z.; Chen, S. L.; Bian, F. L.; Chen, Y.; Wang, B.; Zhan, F. L. \& Liu, S. X. - Acta Physico-Chimica Sinica, 23, p.438 (2007).

18. Teli, S. B.; Gokavi, G. S. \& Aminabhavi, T. M. - Separ. Purif. Tech., 56, p.150 (2007).

19. Shin, Y.; Kim, K. S. \& Kim, B. - Polymer-Korea, 32, p.421 (2008).

20. Biswal, D. \& Hilt, J. Z. - Polymer, 47, p.7355, (2006).

21. Miyata, T.; Asami, N. \& Uragami, T. - Nature, 399, p.766 (1999).

22. Omichi, H. - Nucl. Instrum. Meth. B, 105, p.302 (1995).

23. Moura, M. R.; Rubira, A. F. \& Muniz, E. C. - Polím. Ciência Tecnol. 18, p.132 (2008).

24. Ouwerx, C.; Velings, N.; Mestdagh, M. M. \& Axelos, M. A. V. - Polym. Gels Netw. 6, p.293 (1998).

25. Lee, K. Y.; Rowley, J. A.; Eiselt, P.; Moy, E. M.; Bouhadir, K. H. \& Mooney, D. J. - Macromolecules, 33, p.4291 (2000).

26. Paulino, A. T.; Campese, G. M.; Fávaro, S. L.; Guilherme, M. R.; Tambourgi, E. B. \& Muniz, E. C. - E Polymer, (122), p.1 (2007).

27. Moura, M. R.; Guilherme, M. R.; Campese, G. M.; Radovanovic, E.; Rubira, A. F. \& Muniz, E. C. - Eur. Polym. J. 41, p.2845 (2005).

Enviado: 04/09/08

Reenviado: 25/02/09

Aceito: 02/03/09 